\title{
MULTIPLICAÇÃO in vitro DE Myracrodruon urundeuva Fr. All.: Efeito do BAP e do ANA
}

\section{Rosembrando S. L. Carvalho Filho'; Tecla dos Santos Silva ${ }^{2}$; Thaylane Carneiro Rocha $^{3}$ José Raniere Ferreira de Santana ${ }^{4}$}

1. Bolsista PIBIC/CNPq, Graduando em Agronomia, Universidade Estadual de Feira de Santana, Laboratório de Cultura de Tecidos Vegetais, Unidade Experimental Horto Florestal, e-mail: carvalhoea@ yahoo.com

2. Bióloga, MSc. em Biotecnologia, Doutoranda em Recursos Genéticos Vegetais, Universidade Estadual de Feira de Santana, Laboratório de Cultura de Tecidos Vegetais, Unidade Experimental Horto Florestal, e-mail: silva.stecla@ gmail.com 3. Graduanda em Agronomia, Universidade Estadual de Feira de Santana, Laboratório de Cultura de Tecidos Vegetais, Unidade Experimental Horto Florestal, e-mail: thaylane.car@ hotmail.com

4. Orientador, Departamento de Ciências Biológicas, Universidade Estadual de Feira de Santana e-mail: raniere@uefs.br

PALAVRAS-CHAVE: aroeira-do-sertão; organogênese direta; micropropagação.

\section{INTRODUÇÃO}

Myracrodruon urundeuva Fr. All., conhecida popularmente por aroeira-preta ou aroeira-do-sertão é uma árvore pertencente à família Anacardiaceae (Lima, 2011), que possui madeira de coloração pardo-avermelhada, muito dura e imputrescível, sendo bastante utilizada para obras externas, na construção civil como caibros, tacos para assoalhos, ripas e para peças torneadas (Lorenzi, 1998). A aroeira-do-sertão possui ainda uso medicinal, sendo empregada no tratamento de hemorragias, infecções respiratórias, urinárias e distúrbios no sistema digestório (Matos, 1999).

Em virtude dos múltiplos usos destinados à espécie, esta vem passando por um processo de exploração intensa, de forma predatória, causando a devastação de suas populações naturais. Além disso, a exploração seletiva para uso na indústria madeireira praticamente extinguiu os indivíduos de grande porte (Brandão, 2000), sendo, portanto, considerada uma espécie ameaçada de extinção (MMA, 2008). A cultura de tecidos vegetais possui um papel importante na preservação e multiplicação de espécies nativas que estejam em vias de extinção, visto que através de uma de suas técnicas, a micropropagação, proporciona a obtenção de um número elevado de mudas com estabilidade genética e qualidade fitossanitária, em curto espaço de tempo e em qualquer época do ano.

Auxinas e Citocininas são reguladores de crescimento vegetal utilizados na cultura de tecidos para multiplicação in vitro, sendo BAP (benzilaminopurina) e ANA (ácido alfanaftaleno acético) os mais utilizados. As auxinas atuam na formação e desenvolvimento de raízes adventícias nos caules de segmentos vegetativos de plantas. Já as citocininas, estimulam a divisão, alongamento e diferenciação celular, retardam a senescência das plantas, promovem a quebra da dominância apical e induzem proliferação de gemas axilares. A concentração e o tipo de citocinina influencia diretamente na multiplicação in vitro, além do seu balanço adequado quando há interação entre citocininas e auxinas (Brum et al., 2002).

Nesse contexto, este estudo objetivou avaliar o efeito de diferentes concentrações de BAP e ANA sobre diferentes explantes de M. urundeuva.

\section{METODOLOGIA}

Explantes (cotilédone, hipocótilo e nó cotiledonar) oriundos de plântulas com 30 dias da semeadura foram inoculados em meio de cultura WPM (Lloyd \& Mccown, 1980), contendo 87,64 mM de sacarose, solidificado com 7g. $\mathrm{L}^{-1}$ de ágar e adicionado por distintas concentrações de BAP $(0,0 ; 2,0 ; 4,0 ; 8,0$ e $16,0 \mu \mathrm{M})$ combinados com ANA $(0,0 ; 1,5$ e 3,0 $\mu \mathrm{M})$. O delineamento estatístico foi o inteiramente casualizado (DIC), com arranjo fatorial $3 \mathrm{x}$ 5 x 3 (3 explantes x 5 concentrações de BAP x 3 concentrações de ANA), totalizando 45 tratamentos com 6 repetições, cada uma composta por 5 tubos de ensaio. As culturas foram mantidas em sala de crescimento com temperatura de $25 \pm 3^{\circ} \mathrm{C}$, fotoperíodo de 16 horas e 
radiação fotossintética ativa de $60 \mu \mathrm{mol} \mathrm{m} \mathrm{m}^{-2} \mathrm{~s}^{-1}$. Após 45 dias da inoculação foram avaliados a porcentagem de explantes responsivos para a formação de brotos (\%ER), porcentagem de explantes que formaram calos $(\% \mathrm{FC})$ número de brotos $(\mathrm{NB})$, número de folhas (NF) e comprimento da parte aérea (CPA). Os dados foram submetidos a análise de variância (ANOVA) testando-se as médias pelo teste de Tukey e regressão (fatores qualitativos e quantitativos, respectivamente) com a utilização do software SISVAR (Ferreira, 2011).

\section{RESULTADOS E DISCUSSÃO}

Não foram observadas respostas regenerativas para produção de brotos com o explante cotilédone em nenhum dos tratamentos testados, excluindo-se assim esta variável da análise estatística. A ANOVA demonstrou efeito altamente significativo $(\mathrm{p}<0,01)$ da interação tripla entre os fatores "BAP x ANA x Explantes" para todas as variáveis analisadas, exceto para \%FC, cujo efeito foi não significativo. Comportamento similar foi constatado para a interação entre os fatores duplos "BAP x ANA" e "ANA x Explantes". Os fatores isolados "BAP" e "Explante" apresentaram efeito altamente significativo para todas as variáveis estudadas.

Para \%ER, a maior média $(76,67 \%)$ foi obtida com a utilização do nó cotiledonar na presença de 3,0 $\mu \mathrm{M}$ de ANA combinado com 2,0 e 4,0 $\mu \mathrm{M}$ de BAP. O hipocótilo apresentou baixa taxa de regeneração com os tratamentos testados, com taxa de $0,0 \%$ na maioria destes, atingindo o maior valor médio (36,67\%) em 2,0 $\mu \mathrm{M}$ de BAP na ausência de ANA (Tabela 1). Esses resultados demonstram que a interação dos reguladores de crescimento promoveu um resultado positivo no presente estudo, corroborando Brum et al. (2002) em trabalhos com Figueira (Ficus carica L.), no qual foi evidenciado que a relação auxina/citocinina influenciou diretamente nas respostas in vitro.

As médias para NB demonstraram que o melhor resultado $(1,97)$ foi obtido com 3,0 $\mu \mathrm{M}$ de ANA combinado com 2,0 $\mu \mathrm{M}$ de BAP utilizando-se o explante nó cotiledonar, seguido por 3,0 $\mu \mathrm{M}$ de ANA associado com 4,0 $\mu \mathrm{M}$ de BAP (1,63 broto/explante) e $16 \mu \mathrm{M}$ de BAP na ausência de ANA (1,03 broto/explante) com o mesmo explante (Tabela 1). O número de brotos observado na presença dos fatores combinados BAP e ANA mostram a importância do efeito sinérgico desses reguladores para regeneração a partir do nó cotiledonar na espécie em estudo, no entanto foi observado que em meio isento de auxina também houve formação de brotos, o que se deve provavelmente ao modo da atuação do BAP, onde o mesmo é capaz de promover a quebra da dominância apical e da dormência das gemas laterais culminando, assim, com a formação de novos brotos (George, 1993). O BAP é bastante utilizado em trabalhos de micropropagação de espécies lenhosas, e exemplo de Tectona grandis (Fermino Junior et al. 2014) e Tapirira guianensis (Gutiérrez et al., 2013).

Para a variável NF registrou-se as maiores médias $(7,20$ e 7,03) com o explante nó cotiledonar na presença de 3,0 $\mu \mathrm{M}$ de ANA combinado com 2,0 e 4,0 $\mu \mathrm{M}$ de BAP, respectivamente (Tabela 1). Comportamento similar foi observado para a variável CPA, na qual obteve-se maiores médias $(8,67 \mathrm{~mm}$ e $6,73 \mathrm{~mm})$ também com $3,0 \mu \mathrm{M}$ de ANA combinadas com concentrações $2,0 \mu \mathrm{M}$ e 4,0 de BAP respectivamente, com uso do mesmo explante (Tabela 1). A interação do BAP com a maior concentração de ANA testada evidenciou um acréscimo significativo para o tamanho da parte aérea, demonstrando a importância da interação hormonal nesta variável. No entanto esse resultado difere do obtido por Silva et al. (2013), no qual foi verificado que a adição de reguladores de crescimento vegetal no meio de cultura reduziu o comprimento da parte aérea de Caesalpinia pyramidalis. Pasqual (2001) relata que elevadas concentrações de citocininas podem reduzir o tamanho das brotações. Estas estimulam o brotamento quando aplicada diretamente às gemas axilares de diversas espécies (Taiz \& Zeiger, 2009), consequência da quebra da dominância apical, culminando na redução do tamanho das plantas. 
Tabela 1: Médias para porcentagem de explantes responsivos para a formação de brotos (\%ER), número de brotos (NB), número de folhas (NF) e comprimento da parte aérea (CPA) aos 45 dias obtidos a partir dos explantes hipocótilo (HIP) e nó cotiledonar (NC) de $M$. urundeuva submetidas a diferentes concentrações dos reguladores de crescimento vegetal benzilaminopurina (BAP) e ácido naftalenoacético (ANA). Feira de Santana, BA. 2016.

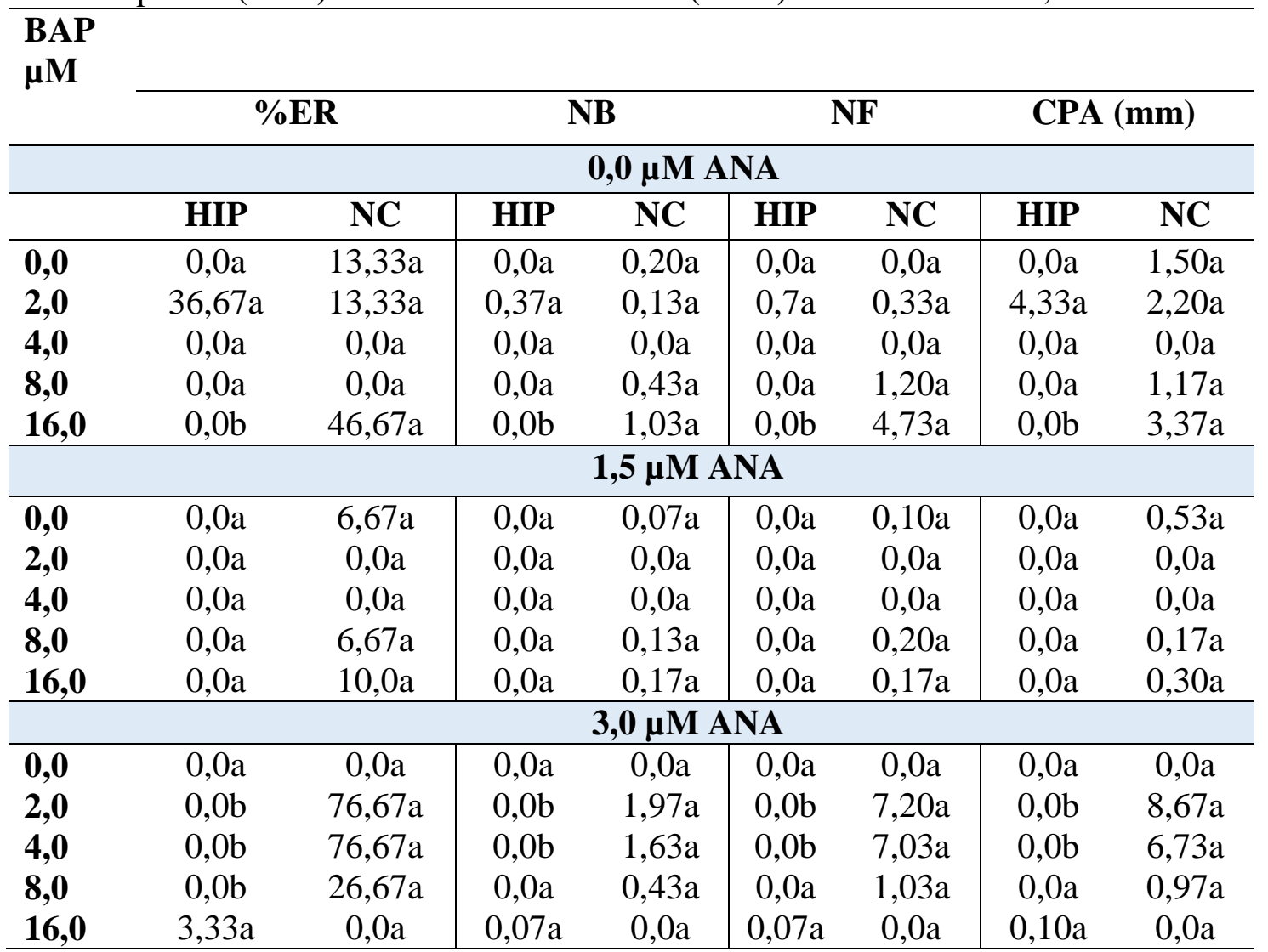

Médias seguidas pela mesma letra na mesma linha para cada variável em relação a cada concentração de ANA, não diferem estatisticamente entre si ao nível de 5\% de probabilidade pelo teste de Tukey.

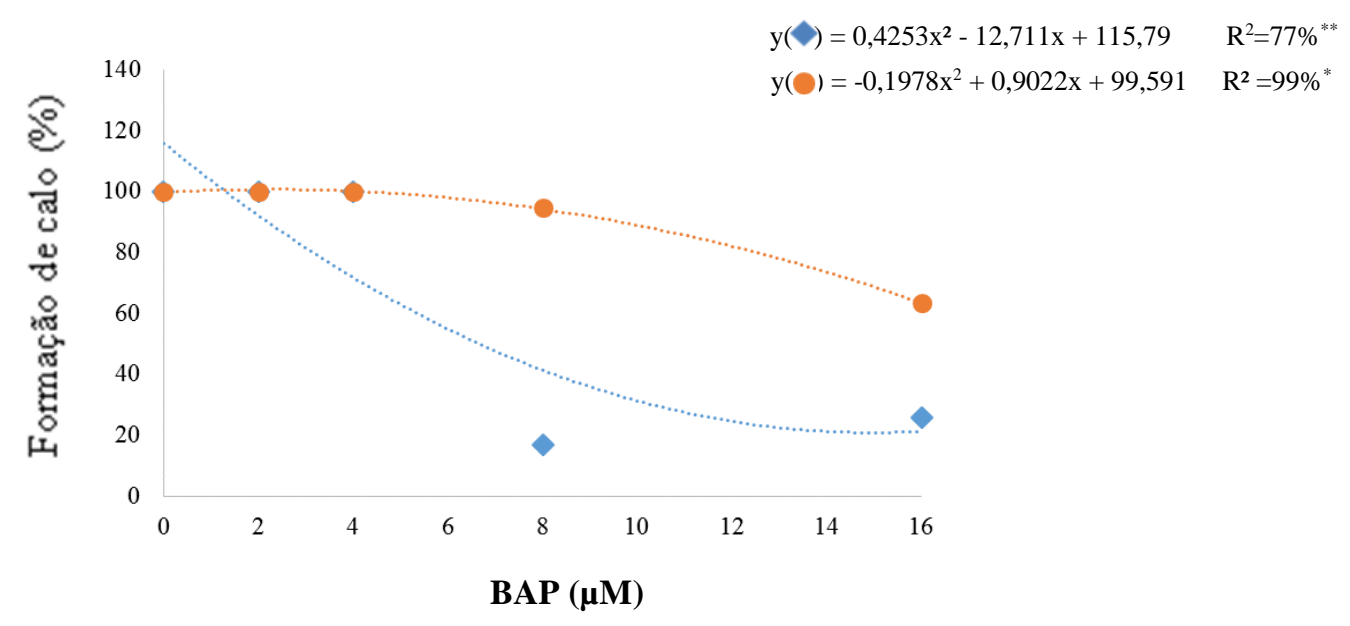

Figura 1: Porcentagem de explantes que formaram calos obtidos a partir dos explantes hipocótilo ( $\diamond$ e nó cotiledonar ( $\mid$ । $M$. urundeuva aos 45 dias com diferentes concentrações de BAP $\left({ }^{* * *}\right.$ significativo ao nível de $1 \%$ e $5 \%$ de probabilidade pelo teste F, respectivamente). Feira de Santana, BA. 2016. 
Para a \% FC, registrou-se comportamento quadrático descendente para o explante hipocótilo, onde foi observada queda na formação de calos com aumento das concentrações de BAP, atingindo menor média $(16,67 \%)$ na presença de $8,0 \mu \mathrm{M}$ de BAP. Para o explante nó cotiledonar, observou-se comportamento quadrático ascendente, sendo registradas altas taxas de $\% \mathrm{FC}$ em todos os tratamentos, ao passo que o menor valor observado $(66,33 \%)$ foi constatado na presença de $16 \mu \mathrm{M}$ de BAP (Figura 1). A formação de calos nos explantes na fase de multiplicação representa um fator negativo causado possivelmente por desbalanços hormonais que se estabelecem entre concentrações de reguladores exógenos com hormônios endógenos, podendo culminar na produção de calos em detrimento de brotos.

\section{CONCLUSÃO}

O uso de 2,0 $\mu \mathrm{M}$ de BAP combinado com 3,0 $\mu \mathrm{M}$ de ANA é indicado na indução de brotos em explante oriundos do nó cotiledonar, no entanto em vista o baixo número de brotos obtidos, sugere-se a realização de outros estudos para aumentar a taxa de multiplicação em M. urundeuva.

\section{REFERÊNCIAS}

BRANDÃO, M. Caatinga. In: MENDONÇA, M. P.; LINS, L. V. (Orgs) 2000. Lista vermelha das espécies ameaçadas de extinção da flora de Minas Gerais. Belo Horizonte: Fundação Biodiversitas e Fundação Zôo-Botânica de Belo Horizonte, p.75-85.

BRUM, G.R.; SILVA, A.B.; PASQUAL, M. 2002. Efeito de diferentes concentrações de BAP e ANA na propagação in vitro da Figueira (Ficus carica L.) Ciênc. Agrotec. Edição Especial: $1403-1409$.

FERMINO JUNIOR, P. C. P.; RAPOSO, A.; NAGAO, E. O.; SCHERWINSKI-PEREIRA, J. E. 2014. Efeito de diferentes citocininas e sistema de cultura dupla-fase na micropropagação de Teca (Tectona grandis L.) estabelecida na Amazônia Sul-Ocidental. Evidência 14 (1): 7 20.

FERREIRA, D. F. 2011. Sisvar: a computer statistical analysis system. Ciência e Agrotecnologia 35 (6): 1039-1042.

GEORGE, E.F. 1993. Plant propagation by tissue culture: the technology. 1.ed. Dordrecht: Springer, 574p.

GUTIÉRREZ, I. E. M.; NEPOMUCENO, C. F.; SILVA, T. S.; FONSECA, P. T.; CAMPOS, V. C. A.; ALVIM, B. F. M.; CARNEIRO, F. S. ALBUQUERQUE, M. S. S.; SANTANA, J. R. F. 2013. Multiplicação in vitro de Tapirira guianensis Aubl. (Anacardiaceae). Revista Ceres 60 (2): 143-151.

LIMA, B. G. 2011. Caatinga: Espécies lenhosas e herbáceas. Mossoró-RN: EDUfersa, 316p. LLOYD, G; McCOWN, B. 1980. Use of microculture for production and improvement of Rhododendronn ssp. HortScience 15(3): 416-420.

LORENZI, H. 1998. Árvores brasileiras: Manual de Identficação e cultivo de plantas arbóreas nativas do Brasil. 2: ed. Nova Odessa: Editora Plantarum, 352 p.

MATOS, F. J. A. 1999. Plantas de medicina popular do Nordeste: propriedades atribuídas e confirmadas. Fortaleza: Edições UFC, 80p.

MMA, Ministério do Meio Ambiente. Instrução Normativa de setembro de 2008. Lista Oficial das Espécies da Flora Brasileira Ameaçadas de Extinção Disponível em: <http://www.mma.gov.br/estruturas/ascom_boletins/_arquivos/83_19092008034949.pdf>. PASQUAL, M. 2001. Textos acadêmicos: meios de cultura. Lavras: FAEPE/UFLA, 127p. SILVA, T. S.; NEPOMUCENO, C. F.; BORGES, B. P. S.; ALVIM, B. F. M.; SANTANA, J. R. F. 2013. Multiplicação in vitro de Caesalpinia pyramidalis (Leguminosae). Sitientibus série Ciências Biológicas 13: 1-6.

TAIZ, L.; ZEIGER, E. 2009. Fisiologia vegetal. 4.ed. Porto Alegre: Artmed, 819p. 